\title{
Concept design - creating an image of the future
}

\author{
Ilya Lepeshkin ${ }^{1, *}$, Alexander Lepeshkin ${ }^{1}$, and Pavel Tarasov ${ }^{1}$ \\ ${ }^{1}$ Moscow Polytechnic University, B. Semenovskaya str., 38, Moscow, 107023, Russia
}

\begin{abstract}
The article presents an analysis of the tasks of industrial design (and in particular the design of vehicles) and demonstrates the importance of developing not only real objects, the purpose of which is to create costeffective products, but also conceptual developments, the tasks of which are much wider. Conceptual developments allow us to form an image of the future, which we want to strive for, to form trends and to demonstrate new opportunities that new technologies open up to us. In this regard, the paper demonstrates a new classification of conceptual developments, as well as the competence of the concept designer who carries out such developments. The classifier contains the division of industrial design, conceptual design and concept art. Conceptual design is concentrated near the border of scientific knowledge, which allows the relevant developments, on the one hand, to be guided by modern high technologies (high technology design), and, on the other hand, to offer solutions that can potentially offer an innovative way of development of a particular field of knowledge, forming a request for new technologies. Competence of a concept designer for such work involves, among other things, the ability to work with the future (futurology) and additional competencies in the field of directing and screenwriting, to create an appropriate visual narrative and convey the value content of the projected image of the future.
\end{abstract}

\section{Introduction}

Modern design, as a field of activity, plays one of the most important roles in shaping the environment and the world around us. At the same time, designers begin to take a direct part in determining the overall vector of development not only of individual industries, such as transport, but also science and technology in general. This profession is becomes more and more popular and today it is difficult to argue with the thesis that the future of the XXI century is called "design" [1, 2].

As more than 150 years ago [3], when the development of technology and industry was the impetus for the formation of design as a science, today the potential of new technologies is extremely high, and therefore they just need to be constantly correlated with a man. At the same time, new technologies rarely pass through the hands of the designer, which in turn inhibits their introduction into the industry and the introduction of new products to the market, because without the potential application these new technologies

\footnotetext{
*Corresponding author: luc-li@yandex.ru
} 
can not successfully develop. It is obvious that for this purpose it is necessary to show to society the perspective technologies and those new opportunities which they can give, to broadcast how life can change if they become available.

Thus, it is important to explore the methods of creating conceptual design developments using future technologies, to learn how to classify these developments, as well as to understand the competencies necessary for concept designers to create these developments and shape the image of the future in order to promote and further develop science and technology in harmony with the individual and society as a whole. The analysis of this process is the purpose of this article.

\section{Discussion of results}

The purpose of industrial design is to "form a harmonious objective environment that best meets the material and spiritual needs of a man" [4]. Design developments are urged to simplify a person's life and solve his everyday problems.

All design developments, of course, are aimed at the future, but in industrial design, this future is often not so distant. At the same time, the main limitations for industrial design are always technological capabilities that are economically justified for a particular group of products. Due to these limitations, the functional and aesthetic aspects of products often suffer, for the implementation of which it is not always possible to choose the appropriate technology or material. The use of advanced technologies in serial development is impossible for most product groups because of their high cost at the first stages of their creation, not to mention those developments that are only now at the research stage, and it may be difficult to apply them simply because of imperfections in technological processes.

Advanced technologies, in turn, due to the fact that they are not yet ready to enter the market, remain unnoticed by any companies or designers, and can not develop properly, because they have not yet formed the demand and sometimes even the range of their applicability is incomprehensible. Scientists and engineers often find it difficult to analyze the possible application of their inventions and, moreover, to assume the reaction of the public to their developments. Therefore, testing a new technology in a new product, as a rule, costs a lot of capital investment and is extremely risky.

Thus, the design developments that we see on the market are in a sector limited by known and proven technologies. The mass consumer, for the most part, is familiar only with the current developments existing within the designated framework, and does not see for himself the prospects and possible benefits that new technologies can give. Information about new developments is interesting only to a small circle of interested people, and is practically not perceived by the public, which in our country is aggravated by the inability of representatives of domestic science to position and broadcast their developments correctly.

A window into the world of future technologies for the public can be the direction of conceptual design (concept design), which can be seen as a cross between the harsh realities of engineering and industrial design and the artistic approach of science-art. (fig. 1) Herewith the concept design function can be two-sided. On the one hand, building a link between society and science will allow "packaging" new technologies in everyday life, and on the other - will allow society to broadcast the request for new technologies. 

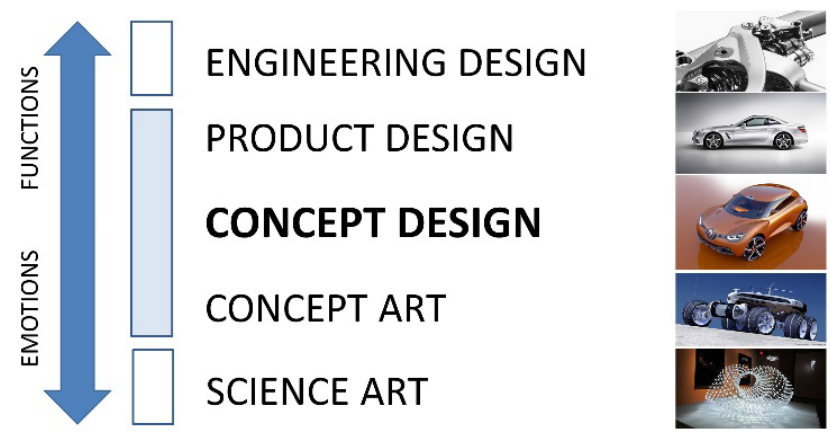

Fig. 1. Distribution of creative activities

The most common is conceptual design (or as it is called "advanced design") in transport design, where all the most famous brands in the world regularly produce new concept cars. In recent years, companies are increasingly offering to the public concepts based not only on new style solutions, but also on new technologies that can radically change our current understanding of transport and "mobility" in general. So, the recent concept from Icona has nothing at all to do with the classic design of the car - there is no steering wheel, no controls - just a cozy room with a chair and a button in which you are, while moving from point A to point B not driving, but in a pleasant, relaxed state (fig. 2) [5].

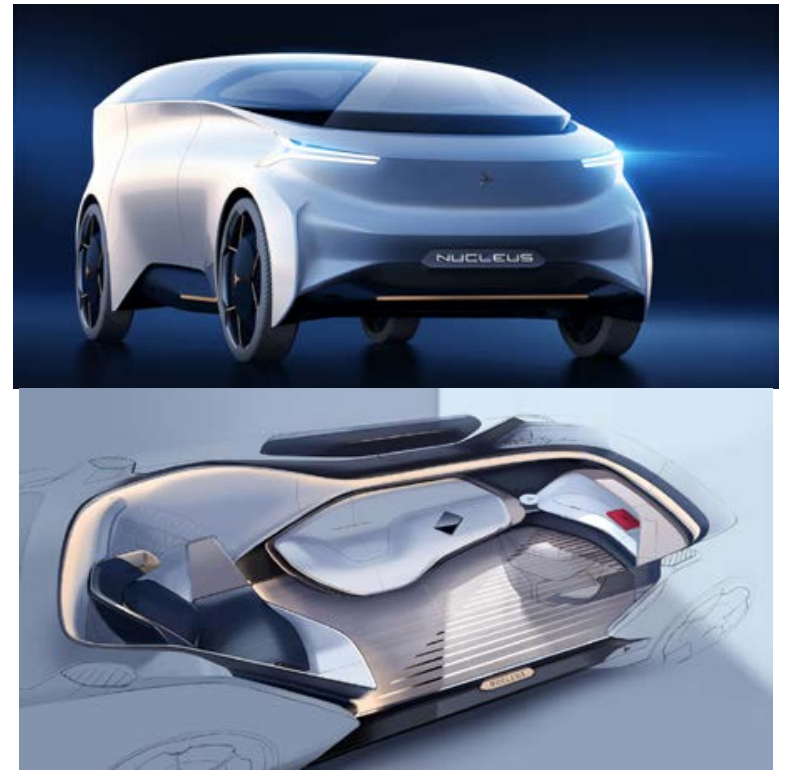

Fig. 2. Icona Nucleus Concept (2018)

Such concept developments appear more often at car shows or are created in the framework of certain competitions. For regular work on their creation, it is obviously required to offer a system of classification of these objects to form their main distinctive features from design developments aimed directly at the current market. Proposals in this direction were made by the author in previous publications $[6,7]$. Today there is a need to expand them and make clarifications in the criteria for the separation of types of design. 
To classify developments in the field of design, the following tool is proposed - Concept DARTS (DARTS - abbreviation of Design-ART-Science) - presented in fig. 3.

In the center of the "target" are developments in the field of industrial design, i.e. everything that corresponds to the basic essence of design and at the same time has economic validity and is aimed at the market. In the direction from the center up to the circle of "economic efficiency" the value of each particular object increases, and it becomes a product more exclusive and in some sense more conceptual. It uses more expensive technologies that cannot yet be implemented in mass production. This allows you to partially avoid restrictions and create more technologically advanced objects.

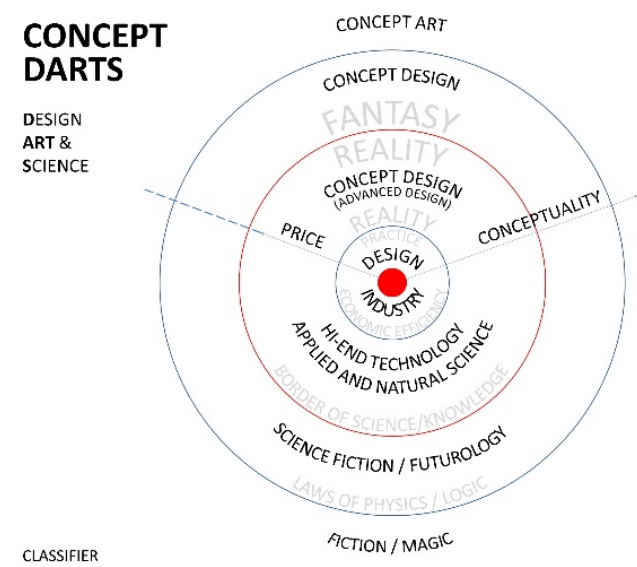

Fig. 3. Classifier of design developments.

Beyond the limits of "economic efficiency " and practical applicability in production lies the area of existing technologies known to science, but remaining out of sight of today's industry, the use of which is now possibly only considered as potential new technologies. Some of them may be even at the research stage, at the very border of human knowledge (the red circle) and their first approbation may be implemented just within the framework of the created concepts. It is these conceptual developments that can be attributed to the "real sector" of conceptual design - perspective design.

The area of perspective design is one of the most difficult in the work of a concept designer, because it is where designers and scientists interact, ready to present their latest developments to the public, even if not as a finished product, but as a possible object with various new characteristics or functions. In fact, this zone can be called "high-tech design".

It is obvious that as soon as the principles on which this or that development is based, are beyond reality and scientific knowledge of mankind, the boundless world of imaginations opens before us, where only restriction is a human logic. It makes it possible to explain, based on different laws and principles, the actions of a phenomenon. This area is often associated with "science fiction", and design, creating a world of things that work on the basis of these assumptions (expectations), should be attributed to the "fantastic sector " of conceptual design, the field of designing new principles, patterns and meanings.

In this sector, the task of concept design is to stimulate the development of science and technology, demonstrating the fantastic world that can not be realized yet. It demonstrates the benefits that this world offers to humanity, as well as the new functionality and new experiences that can change our lives. Such developments create a motivational background for the development and work of scientists today and in the future. In fact, the designer here himself plays the role of a scientist, inventing new materials, creating new technologies and architecture of objects, setting new principles that today may seem fantastic, but after a 
certain number of years to be prophetic in a particular industry, as once did science fiction writers during the industrial revolution in the XIX century [8].

Everything that is on the scheme beyond logic and the ability of the designer to explain the essence of the technology and/or the principle of operation of a phenomenon, is in the field of fiction or concept art, where the only explanation for the question "how does it work?” could be the phrase "it's magic...”.

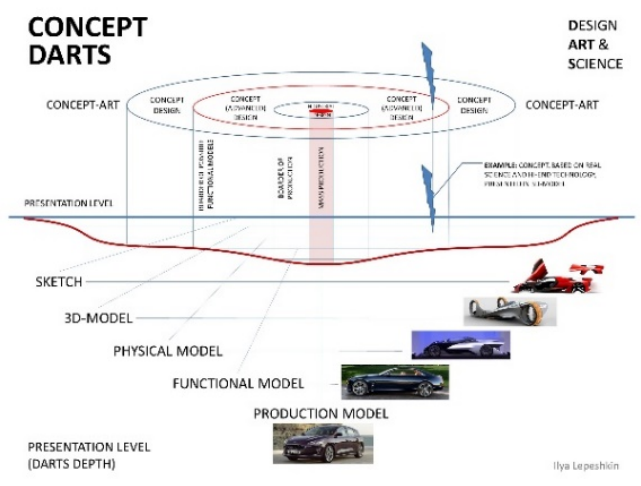

a

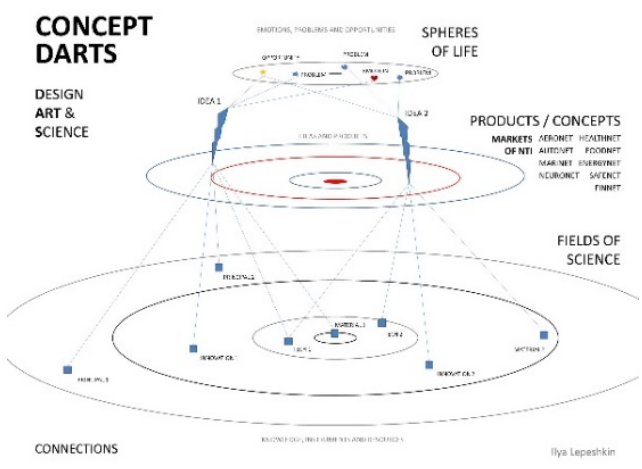

b

Fig. 4. a). Level of elaboration of design solutions. b) Scheme of interrelations of design developments, scientific principles and society.

It should be noted that for each zone on this target, different degrees of elaboration and visualization of objects are possible. For example, for concepts from the fantasy zone it is impossible to create a functional model (prototype), because these technologies do not yet exist, which means that for the level of "magic" it is not always possible even to perform their 3D model, because it is difficult to give shape to something that does not know on what principles it functions. This separation is shown in fig. $4 \mathrm{~A}$.

To work with the presented classifier, it is necessary to understand the system in which this or that development is implemented, and the relationships that are formed when creating a new design. If we translate this scheme into volume format, and if we assume that on the central (core) "target" are the design developments, the lower part will be "technological target", and the top part will be "social target" (fig. 4B). This design allows you to visualize in the best way that each design development is aimed at solving a particular problem of society or of a particular person, or at the formation of new opportunities and is based on different technologies and principles. Given the fact that "technological target" has the same zones, which we talked about earlier (the 
reality/fantasy/magic), then using this scheme you can easily classify each concept by affiliating technology or principle underlying its basis, to a particular area of "technological target”.

We should also note that the sectors of the target data can be divided in different ways, depending on the desired result. Within the framework of this article, it is possible to propose a division by NTI markets (NTI - the National Technology Initiative), which can allow to classify various promising developments for the near future.

Thus, the most interesting for us is the concept design zone (real (perspective) and fantastic), and especially the zone near the border of the "cutting edge of science". Here the designer balances on the edge of existing technologies and at the same time puts a request for their development and improvement or allows (and partly anticipates) the possible emergence of new discoveries and breakthroughs in certain areas of science.

This partly unites concept designer with futurologists, whose task is to build the trajectories of science, technology, society and predict the emergence of new technologies and explore how they will affect all areas of human life.

In general, the competence of the concept designer should be a priori wider than the competence of industrial designers and include a combination of basic skills from different fields of activity. The competence model of such a concept designer is presented in fig. 5A. It combines a major triad of related areas, which the designer combines engineer/artist/marketer, and a triad of specialties that the futurist combines scientist/philosopher/sociologist. It is the combination of these competencies that forms the complete image of the conceptual designer.

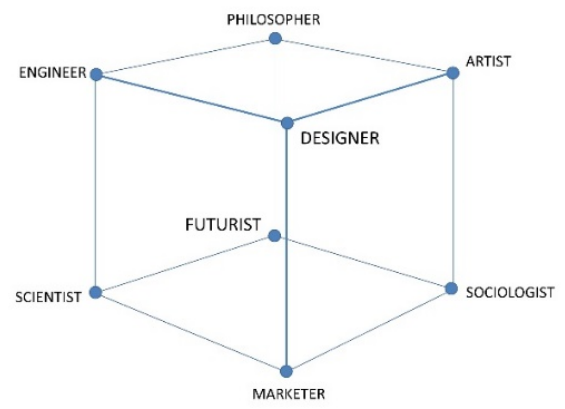

a)

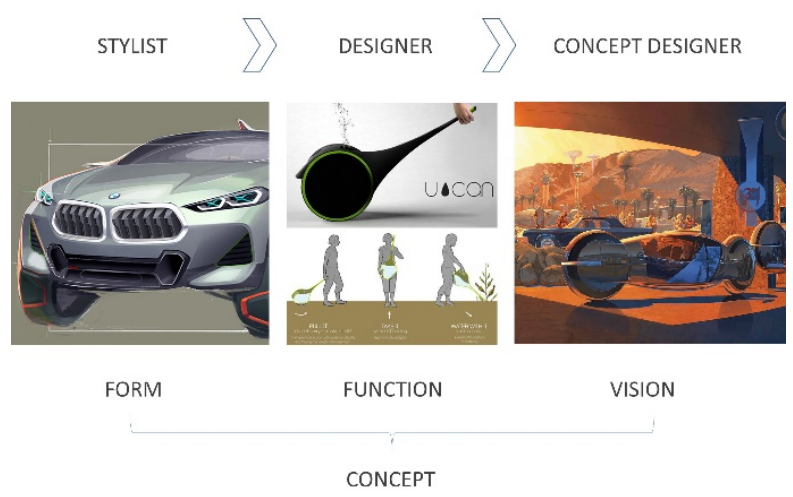

b)

Fig. 5. a). Competence model of a conceptual designer. b). Functions of a designer 
Thus, the design profession has a new function, which clearly shows the "stretch" between today's designer (whose function in some industries is often understood only to perform stylistic study of the developed object (decoration)) and the concept designer. The latter, in addition to the main task of the industrial designer to create a new object with new functionality and architecture, has the function of developing a vision of the future, creating a new environment and the world as a whole (fig. 5B).

A distinctive feature of concept designers is their ability to design new objects using new technologies (regardless of the initial conditions laid down in the framework of the "terms of reference"), as well as to visualize what does not yet exist and present the project in such a way that it is accessible to the public and achieves its goal. Popularization of new technologies or checking the public reaction to these promising developments can serve as the examples.

It is extremely important to emphasize that the demonstration of the project for the concept designer is even more important than for the usual industrial or transport designer. This is because though an industrial designer describes problem scenarios in the life of the user or usage of an object, but he interacts with real conditions known to most people in the reality, where there is no need to describe the principles of organization of the environment, or new principles of interaction and functioning of objects. The concept designer, in turn, must necessarily describe and visualize the proposed new world of the future, immerse the "audience" in it and, accordingly, pack the concept he is developing into the story that will help them to form a holistic view of a new technology or a new product.

Thus, extremely important competencies for the concept designer are the ability to work with the future (futurology), as well as visual storytelling and some competencies from the field of directing and screenwriting skills to create interesting stories and work with the attention of the viewer.

\section{Conclusion}

Concept design is one of the current trends in design. Its interests are much wider than the work of an ordinary industrial designer. It includes all the aspects necessary to create a new world and the breadth of coverage can be comparable to the design as a whole, with the only difference that the objects are not developed for today, but for the future, in which there may be other living conditions, other technologies, and may even act the laws of nature unknown to us today. Concept design allows you to create a range of options and alternatives that can describe the future to which we will come, provided the implementation of certain concepts (fig. 6).

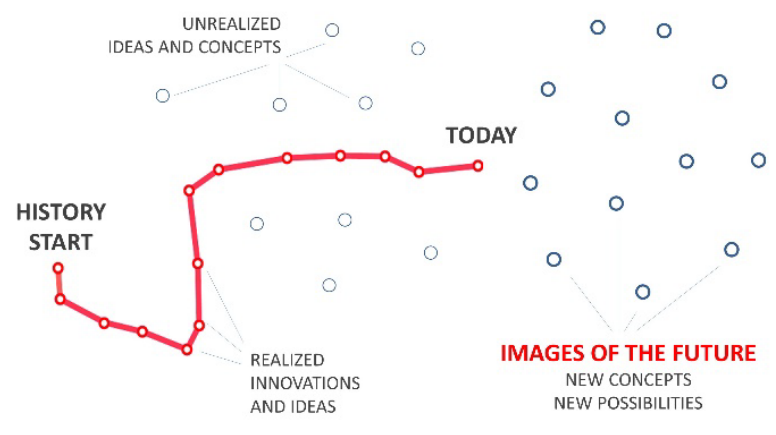

Fig. 6. The path of history and alternative images of the future 
Thus, conceptual design should take a leading, anticipatory position in the formation of the image of the future, show new technologies in the context of their applicability and clearly demonstrate the process of transformation of today's world, as well as convey this image to people to jointly and consciously go to the realization of a particular image of the future.

\section{References}

1. https://bazaar.ru/lifestyle/design/anastasiya-butrym-u-dizaynerov-nastupaet-samayazahvatyvayushchaya-praktika-v-istorii-chelovechestva-ih-rol-stanovitsya-absolyutnoy

2. https://mel.fm/blog/gadzhetina-piarlevich/65849-professii-nastayushchego-kontseptkhudozhnik

3. https://ru.wikipedia.org/wiki/дизайн

4. https://studbooks.net/1028001/kulturologiya/tseli_zadachi_dizayna

5. http://www.icona-designgroup.com/en/portfolio/nucleus-interior/

6. I.A. Lepeshkin, Classifier of design developments in the field of transport design. Izvestiya MSTU "Mami", No. 1(11), pp. 59-67 (2011)

7. I.A. Lepeshkin, M.Yu. Ershov, Classification of concept arts and concepts in transport design. ENI RTP ELECTRONIC SCIENTIFIC PUBLICATION “Design. Theory. Practice”. Issue 7, pp. 38-59 (2011). www.enidtp.ru

8. I.A. Lepeshkin, S.M. Kruglov, The History of concept arts and concepts in transport design. Izvestiya MSTU "Mami". No. 2(20), pp. 82-87 (2014) 